\title{
Influence of low-stress handling on reactivity score and pregnancy rate during fixed-time artificial insemination in Nellore cows
}

\author{
Rayf Roberto Tirloni ${ }^{1}$, Fábio Alcântara Rocha ${ }^{1}$, Fábio José Lourenço ${ }^{1}$, Lílian Rigatto Martins ${ }^{1}$ \\ ${ }^{1}$ Universidade Federal de Mato Grosso - UFMT, Campus Sinop, Laboratório de Reprodução Animal, Avenida Alexandre Ferronato, 1200. Sinop, \\ Mato Grosso, Brazil.
}

\begin{abstract}
The objective of this work was to evaluate the influence of low-stress handling (LSH) on reactivity score and pregnancy rate during fixed-time artificial insemination (FTAI) for extensively raised Nellore cows. Multiparous cows $(\mathrm{n}=126)$ were randomly allocated into two groups: G1 $(n=66)$ and G2, the control group $(n=60)$. Group G1 was subjected to LSH, in which the animals were handled in a calm and quiet manner, without loud noises or physical aggression, using the point of balance, respecting the flight zone and using flags to supplement handling. Group G2 was handled following the typical procedure, with yelling, kicking and the use of electric prods and sticks. On D0, D8 and D10, FTAI was performed in both groups. Reactivity was scored on D0, D8 and D10 at the squeeze chute, based on the tension score, breathing score, and bellowing score. Using the three criteria above, the reactivity scores were defined as follows: R1 (calm); R2 (slightly reactive); R3 (moderately reactive); R4 (reactive); and R5 (highly reactive). Thirty-five days after artificial insemination, pregnancy was determined using ultrasonography. There was no significant correlation between reactivity score and pregnancy rate in each group or between the pregnancy rates in both groups. However, there was a statistically significant difference between the G1 and G2 groups with regard to reactivity score $(1.62 \pm 0.05$ vs. $2.12 \pm 0.07)$. Low-stress handling influenced reactivity but did not affect pregnancy rate in extensively raised Nellore cows subjected to FTAI.
\end{abstract}

Key Words: Bos indicus cattle, conception, reaction, reproduction, stress

\section{Introduction}

The reproductive process requires constant contact with the animals during critical moments when stress may have negative effects on reproductive efficiency. It is inevitable that aversive practices, such as vaccination, branding, castration or even artificial insemination, will occur during the life of an animal (Costa e Silva, 2004; Macedo et al., 2011). Stress can also have detrimental effects in the form of cessation of growth and reproduction once the pituitaryadrenal system is sensitized to environmental stressors (Dantzer \& Mormède, 1983).

There is endocrinal evidence showing that stressors interfere with the precise timing of reproductive hormone release during the follicular phase. The reduction in the $\mathrm{LH}$ pulse frequency suggests that both of these stressors affect GnRH pulsatile secretion (Dobson \& Smith, 2000).

Zebu cattle are more reactive than animals from temperate areas (Cafe et al., 2011), and Nellore cattle are a suitable model to study because they are often exposed to different stress situations, which may compromise reproduction (Macedo et al., 2011).

Low-stress handling (LSH) includes techniques such as silence, flag handling and adequate restraint, which minimize the stress of the feedlot environment and prevent stress levels that would increase aggressive reactions toward operators. It also uses the point of balance and respects the flight zone. Any invasion of this zone causes the animal to move away from the intruder. In extremely tame animals, the flight zone that surrounds the animal may be extremely small. The position of the body of the handler within the flight zone determines the direction toward which the animal will move. If the animal is approached from a point behind its shoulder (point of balance) it will most likely move forward, angling to the opposite side of the handler (Mikesell \& Baker, 2011).

Although fixed-time artificial insemination (FTAI) is a relatively simple process, cattle must be handled several times, and the contact with ranchers and feedlot operators is intensive. Low-stress handling is a useful tool for minimizing FTAI handling. Before an FTAI procedure, these techniques can be performed more rapidly and safely than conventional handling to avoid direct losses or indirect losses, such as reduced pregnancy rate (Lindahl et al., 2012; Paranhos da Costa, 2002; Walker et al., 2010).

The objective of this study is to evaluate the influence of low-stress handling on reactivity score and pregnancy rate after FTAI for extensively raised Nellore cows. 


\section{Material and Methods}

All procedures in this trial were approved by the Ethics Committee of Animal Research (CEPA) of Universidade do Mato Grosso, Brazil.

Multiparous Nellore cows $(n=126)$ were evaluated using a body condition score (BCS) ranging from 1 to 9 (Wiltbank, 1983), and those that exhibited a BCS between 6 and 7 were selected and randomly allocated to two groups: G1 $(n=66)$, the experimental group, and G2 $(n=60)$, the control group. The cows were acclimated for two weeks before the beginning of the treatment, which lasted 10 days. Throughout the experimental period, all animals were driven in a single group every day from the pasture to a holding yard adjacent to the facilities. Both groups were raised under tropical conditions at extensive pasture system and maintained in a paddock (Brachiaria brizantha cv. Piatã) with an available area of $110 \mathrm{~m}^{2}$ per animal, adjacent to the cattle working facilities and the holding yard, with mineral supplementation and water ad libitum as well as good natural shading.

Group G1 was subjected to low-stress handling, in which the animals were handled in a calm and quiet manner, avoid isolating individual animals, without loud noises or physical aggression, using the point of balance, respecting the flight zone and using flags to supplement handling, moving small bunches in a slow walk and using the following behavior as reviewed by Grandin (1998). Group G2 was handled as usual during the operation, with yelling, kicking and using electric prods (PPH3 ${ }^{\circledR}$, Magnatronic, Paraná, Brazil) and sticks.

On D0, all animals were given progesterone-releasing intravaginal device $\left(1.0 \mathrm{~g}\right.$ progesterone, Primer, Tecnopec ${ }^{\circledR}$, São Paulo, Brazil) and estradiol benzoate (2 mg; RICBE, Tecnopec ${ }^{\circledR}$, São Paulo, Brazil). Eight days after, progesterone-releasing intravaginal devices were removed and cows were given d-cloprostenol $(150 \mu \mathrm{g}$, i.m. Prolise, Tecnopec $^{\circledR}$, São Paulo, Brazil), estradiol benzoate (1 mg; i.m., RIC-BE, Tecnopec ${ }^{\circledR}$, São Paulo, Brazil) and FSHp
(10 mg, i.m..., Folltropin, Tecnopec ${ }^{\circledR}$, São Paulo, Brazil). Forty-eight hours later, the same operator concurrently inseminated all animals using semen straws from the same bull and the same match.

On D0, D8 and D10, reactivity was scored at the squeeze chute, according to Costa e Silva et al. (2010), as R1, R2, $\mathrm{R} 3, \mathrm{R} 4$ or R5, and it was calculated based on the tension score $(1=$ relaxed - absence of abrupt movements of head and/or tail; 2 = restless - presence of abrupt movements of head and/or tail; $3=$ very restless - muscular trembling), breathing score $(1=$ not audible; $2=$ audible and deep; $3=$ snorting/snoring - deep breathing with sound emission) and bellowing score $(0=$ absence of bellowing; $2=$ presence of bellowing) (Table 1).

Thirty-five days after artificial insemination, all of the cows were examined ultrasonically, using a real-time ultrasonograph (HS 1500V, Honda ${ }^{\circledR}$, Toyohashi, Japan) with a $7.5 \mathrm{MHz}$ transrectal transducer (HLV 375M, Honda ${ }^{\circledR}$, Toyohashi, Japan).

The data were evaluated using a generalized linear model, assuming a distribution function of binomial probability and a logistic link function. Our hypothesis was tested using Fisher's exact test.

Pregnancy was evaluated as a function of the day, group and reactivity using the following model:

$$
\begin{gathered}
\text { Yijkl }=u+D i+G j+R k+D G i j+D R i k+G R j k+ \\
\text { DGRijk }+ \text { eijkl }
\end{gathered}
$$

where: $Y i j k l=$ pregnancy diagnosis of the animal $i j k l$; $\mathrm{u}=$ overall mean; $\mathrm{Di}=$ day $\mathrm{i} ; \mathrm{Gj}=$ group $\mathrm{j} ; \mathrm{Rk}=$ reactivity $\mathrm{k}$; DGij = interaction between day $\mathrm{i}$ and group $\mathrm{j}$; DRik = interaction between day $\mathrm{i}$ and reactivity $\mathrm{k}$; GRjk = interaction between group $\mathrm{j}$ and reactivity $\mathrm{k}$; DGRijk = interaction between day $\mathrm{i}$, group $\mathrm{j}$ and reactivity $\mathrm{k}$; and eijkl $=$ error associated with observation $\mathrm{ijkl}$.

The model used to analyze pregnancy diagnosis as a function of the handling type was:

$$
Y i j=u+T i+e i j
$$

where: $Y \mathrm{ij}=$ pregnancy diagnosis result of animal $\mathrm{ij} ; \mathrm{Ti}=$

\begin{tabular}{|c|c|c|c|}
\hline \multirow{2}{*}{ Reactivity } & \multicolumn{3}{|c|}{ Score } \\
\hline & Tension & Breathing & Bellowing \\
\hline R1 (calm) & 1 & 1 or 2 & 0 or 1 \\
\hline R2 (slightly reactive) & 1 (if breathing $\geq 2$ ) & 1,2 , or 3 (if bellowing $=0$ ) & 0 or 1 \\
\hline R3 (moderately reactive) & 1 (if bellowing $\neq 0$ ) or 2 & 1,2 or 3 (if bellowing $=0$ ) & 0 or 1 \\
\hline R4 (reactive) & 2 (if bellowing $\neq 0$ ) or 3 & 1,2 or 3 (if bellowing $=0$ ) & 0 or 1 \\
\hline R5 (highly reactive) & 3 (if bellowing $\neq 0$ ) & - & - \\
\hline
\end{tabular}
handling type; and eij = error associated with observation $\mathrm{ij}$.

Table 1 - Reactivity score based on tension, breathing and bellowing score

Adapted from Costa e Silva et al. (2010). 


\section{Results and Discussion}

The type of handling did not influence pregnancy rates, which were $56.66 \%$ and $50.00 \%$ for traditional and lowstress handling, respectively.

There was no significant correlation $(\mathrm{P}>0.05)$ between reactivity score and pregnancy rate in either group or between the pregnancy rates in both groups. However, there was a statistically significant difference $(\mathrm{P}<0.05)$ between the G1 and G2 groups with regard to reactivity score (1.62 \pm 0.05 vs. $2.12 \pm 0.07)$.

There was no significant difference between pregnancy rates and the different reactivity scores (Table 2).

There was also no significant difference between the day of FTAI protocol and reactivity score (Table 3).

Warriss et al. (1994) showed that subjective assessments of the stress experienced by pigs and objective measurements of the sound level produced immediately before stunning strongly correlate with objective indices of stress. The same authors demonstrated that blood measurements are poorly defined indices of stress, due to the time course and pattern of response to different types and intensities of stress.

Handling influence on reactivity was observed by Becker \& Lobato (1997), who subjected calves to repeated behavioral evaluations. The data included time spent moving, observation period, increase of flight distance, aggression and attack toward the feedlot operator. The same authors demonstrated that calves that were not handled in a gentle way presented more aggressive behavior toward feedlot operators than those subjected to low-stress handling. They concluded that such results suggest that habituation to the handling routine and the use of low-stress handling is an important factor in stress reduction.

The interaction of stress physiology with reproduction has been the target of recentstudies. It has been demonstrated that acute or chronic stress may affect follicular dynamics and corpus luteum function, inhibiting GnRH release, and consequently LH release, via the hypothalamus (Battaglia et al., 1997; Breen \& Karsh, 2003).

However, a study conducted by Grandin (1983) showed that habituation to a stressor is dependent on its

Table 2 - Pregnancy rate in relation to reactivity score in Nellore cows subjected to FTAI

\begin{tabular}{lc}
\hline Reactivity score & Mean pregnancy rate (\%) \\
\hline R1 & 45.9 \\
R2 & 59.5 \\
R3 & 60.4 \\
R4 & 60.0 \\
\hline
\end{tabular}

Fisher's exact test $(\mathrm{P}<0.05)$

FTAI - fixed-time artificial insemination. type, intensity, duration, and the previous experience of individual animals. For this reason, not all individuals react in the same way to the same environmental changes (Solano et al., 2004).

In the present study, there was no correlation between pregnancy rate and reactivity score. The criterion used by the owner of the animals to select them along the years is docility; therefore it is likely that the traditional handling did not cause enough stress to cows to interfere with their reproduction.

Solano et al. (2004) observed that, in some species including the bovine, which seem to experience a relative nonaggressive society behavior such as subordinance, no association with a chronically overactive stress response has been reported. The issue is whether some other reproductive parameters might present the same pattern.

Additionally, Hargreaves \& Hutson (1990) question whether a physiological response alteration is either the effect of changing perceptions of the stimulus or the repeated elevation of physiological parameters.

Another possible explanation for the similar pregnancy rates observed in the traditional and low-stress handling groups is that maybe these animals were not exposed to the stressful management long enough to result in a poor pregnancy rate.

Neuroendocrine stress responses are regulated by the hypothalamic-pituitary-adrenal axis, which promotes plasmatic cortisol release (Curley et al., 2008). This response is vital to an organism that has to cope with a challenging environment (Abbot et al., 2003). However, in a study conducted by Andrade et al. (2001) it was shown that it takes a 19-day trial period to observe a decrease in cortisol concentrations in Zebu cattle.

It has been described that immediately before the cows come into standing estrus is the time in which management stress may have its biggest effect on reproduction (Varner, 2012). Animals of this trial were handled in four different moments during a fixed-time artificial insemination, including immediately prior to estrus. It may be speculated that the females might have already had their response stabilized after some initial familiarization with handling and facilities, reflecting in similar pregnancy rates in both groups.

Table 3 - Relation between mean reactivity score and the day of FTAI protocol

\begin{tabular}{lc}
\hline Day of FTAI protocol & Mean reactivity score \pm SEM \\
\hline 0 & $2.07 \pm 0.09 \mathrm{a}$ \\
8 & $1.85 \pm 0.08 \mathrm{a}$ \\
10 & $1.65 \pm 0.07 \mathrm{a}$ \\
\hline
\end{tabular}

Fisher's exact test $(\mathrm{P}<0.05)$

FTAI - fixed-time artificial insemination; SEM - standard error of the mean. 
According to Dobson et al. (2001), studying the effects of stress on reproduction is beset with difficulties. This may explain the similar pregnancy rates between groups. The complex nature of the modern farm environment simultaneously exposes animals to several different stressor stimuli. Furthermore, there is considerable variability in the response of an individual to a given stimulus.

Reactivity score was different between groups, although it had no influence on pregnancy rate. Betweenanimal variation in stress responsiveness could also be high in cattle (Mormède et al., 2007); however, little is known as to whether this relates to different assessments of temperament (Curley et al., 2008). This information reinforces the idea that not all animals cope in the same way with the environment, which is relevant to the improvement of herd management practices (Abbot et al., 2003).

\section{Conclusions}

Although low-stress handling influences reactivity, it does not affect the pregnancy rate in extensively raised Nellore cows subjected to fixed-time artificial insemination. Further studies are required to determine the influence of exposing animals to stressful management long enough on pregnancy rates. However, we emphasize that improving welfare conditions of cows at the reproduction centers/ facilities is a valuable tool to minimize reproductive losses and increase productivity.

\section{References}

ANDRADE, O.; ORIHUELA, A.; SOLANO, J. et al. Some aspects of repeated handling and the use of a mask on stress responses in zebu cattle during restraint. Applied Animal Behaviour Science, v.71, p.175-181, 2001

ABBOT, D.H.; BARNETT, D.K.; COLMAN, R.J. et al. Aspects of common marmoset basic biology and life history important for biomedical research. Comparative Medicine, v.53, p.339-350, 2003.

BATTAGLIA, D.F.; BOWEN, J.M.; KRASA, H.B. et al. Endotoxin inhibits the reproductive neuroendocrine axis while stimulating adrenal steroids: A simultaneous view from hypophyseal portal and peripheral blood. Endocrinology, v.138, p.4273-4281, 1997.

BECKER, B.G.; LOBATO, J.F.P. Effect of gentle handling on reactivity of zebu crossed calves to humans. Applied Animal Behaviour Science, v.53, p.219-224, 1997.

BREEN, K.M.; KARSH, F.J. Does cortisol inhibit pulsatile luteinizing hormone secretion at the hypothalamic or pituitary level? Endocrinology, v.145, p.692-698, 2003.

CAFE, L.M.; ROBINSON, D.L.; FERGUSON, D.M. et al. Cattle temperament: persistence of assessments and associations with productivity, efficiency, carcass and meat quality traits. Journal of Animal Science, v.89, p.1452-1465, 2011.

COSTA E SILVA, E.V. Estresse e manejo reprodutivo de bovinos de corte: problemas e soluções. In: SIMPÓSIO DE PRODUÇÃO DE GADO DE CORTE, 4., 2004, Viçosa, MG. Anais... Viçosa, MG: Universidade Federal de Viçosa, 2004. p.459-484.

COSTA E SILVA, E.V.; KATAYAMA, K.A.; MACEDO, G.G. et al. Efeito do manejo e de variáveis bioclimáticas sobre a taxa de gestação em vacas receptoras de embriões. Ciência Animal Brasileira, v.11, p.280-291, 2010.

CURLEY, K.O.; NEUENDORFF, D.A.; LEWIS, A.W. et al. Functional characteristics of the bovine hypothalamic-pituitaryadrenal axis vary with temperament. Hormones and Behavior, v.53, p.20-27, 2008.

DANTZER, R.; MORMÈDE, P. Stress in farm animals: A need for reevaluation. Journal of Animal Science, v.57, n.6, p.6-18, 1983.

DOBSON, H.; SMITH, R.F. What is stress, and how does it affect reproduction? Animal Reproduction Science, v.60/61, p.743-752, 2000.

DOBSON, H.; TEBBLE, J.E.; SMITH, R.F. et al. Is stress really all that important? Theriogenology, v.55, p.65-73, 2001.

GRANDIN, T. Behavioral agitation during handling of cattle is persistent over time. Applied Animal Behavior Science, v.36, p. $1-9,1983$.

GRANDIN, T. Review: reducing handling stress improves both productivity and welfare. Professional Animal Science, v.14, p.1-10, 1998.

HARGREAVES, A.L.; HUTSON, G.D. Some effects of repeated handling on stress responses in sheep. Applied Animal Behavior Science, v.26, p.253-265, 1990 .

LINDAHL, C.; LUNDQVIST, P.; NORBERG, A.L. Swedish dairy farmers' perceptions of animal-related injuries. Journal of Agromedicine, v.17, p.364-376, 2012.

MACEDO, G.G.; ZÚCCARI, C.E.; DE ABREU, U.G. et al. Human animal interaction, stress, and embryo production in Bos indicus embryo donors under tropical conditions. Tropical Animal Health and Production, v.46, p.1175-11822, 2011.

MORMÈDE, P.; ANDANSON, S.; AUPÉRIN, B. et al. Exploration of the hypothalamic-pituitary-adrenal function as a tool to evaluate animal welfare. Physiology \& Behavior, v.92, p.317-339, 2007.

MIKESELL, R.; BAKER, M. Animal science biology and biotechnology. 3.ed. New York: Delmar, 2011. 666p.

PARANHOS DA COSTA, M.J.R. Ambiência e qualidade de carne. In: CONGRESSO DAS RAÇAS ZEBUÍNAS, 5., 2002, Uberaba. Anais... Uberaba: ABCZ, 2002. p.170-174.

SOLANO, J.; GALINDO, F.; ORIHUELA, C.A. et al. The effect of social rank on the physiological response during repeated stressful handling in Zebu cattle (Bos indicus). Physiology \& Behavior, v.82, p.679-683, 2004.

VARNER, M.A. [2012]. Stress and reproduction. In: Dairy integrated reproductive management. Available at: <www.wvu.edu/ãgexten/ forglvst/.../dirm15.pdf $>$ Accessed on: Jan. 25, 2013.

WALKER, S.L.; SMITH, R.F.; JONES, D.N. et al. The effect of a chronic stressor, lameness, on detailed sexual behavior and hormonal profiles in milk and plasma of dairy cattle. Reproduction in Domestic Animals, v.45, p.109-117, 2010.

WARRISS, P.D.; BROWN, S.N.; ADAMS, S.J.M. Relationships between subjective and objective assessments of stress at slaughter and meat quality in pigs. Meat Science, v.38, p.329-340, 1994.

WILTBANK, J.N. Effect of nutrition and other factors on the reproduction heifers. In: ANNUAL BEEF CATTLE SHORT COURSE, 26., 1983, Gainesville, FL. Proceedings... Gainesville: University of Florida, 1983. p.63-68. 